\title{
A cost description of an adult cystic fibrosis unit and cost analyses of different categories of patients
}

\author{
Mark Robson, Janice Abbott, Kevin Webb, Mary Dodd, Joanna Walsworth-Bell
}

\begin{abstract}
Background There is little information on the costs of running an adult cystic fibrosis centre. The aim of this study was to provide detailed costings to assist funding and planning for these patients. Methods The cost of a regional adult cystic fibrosis centre serving 119 cystic fibrosis patients, categorised according to four treatment regimens, was determined. District health authority, family health service authority, and voluntary resources used from April 1989 to March 1990 were determined, with appropriate bases for allocation of costs and patient based costings from local information. Results The total annual cost of treating the 119 patients was $f 980646$, with an average cost $£ 8241$ per patient. An outpatient reviewed at three monthly intervals cost $£ 2792$ a year; an outpatient receiving intravenous antibiotics cost £8606; an inpatient receiving intravenous antibiotics cost $£ 13$ 501; and a patient needing a high level of care cost $£ 19955$. Medication accounted for $57 \%$ ( $£ 561395$ ) of the total cost.

Conclusions This analysis has helped us to secure funding for patients with cystic fibrosis and it facilitates the prediction of future requirements. The study also indicates the limitations of using average patient costs and dificulties as a result of the poorly structured British National Health Service accounting and information systems.
\end{abstract}

\section{('Thorax 1992;47:684-689)}

Nearly all patients with cystic fibrosis seen in large clinics in the United Kingdom ${ }^{1}$ and specialist centres in other countries survive into adult life. ${ }^{2-4}$ The adult cystic fibrosis unit at Monsall Hospital in Manchester receives paticnts over 16 years of age from North West England and North Wales. The unit was established in 1982 to provide continuity of care by taking over from two paediatric cystic fibrosis centres. ${ }^{5}$ The number of patients has increased steadily and the unit currently manages over $80 \%$ of adults with cystic fibrosis in the North Western Region. The regional pacdiatric register indicates that the number of adult patients will continue to increase. The unit comprises physicians, nurses, physiotherapists, a dietician, and social workers, and relies heavily on local district health authority services, such as radiology and pathology.
Three major factors stimulated this study: the recent loss of the unit's regional status, the impending implementation of "contracting" as outlined in the government white paper for England and Wales entitled Working for patients, ${ }^{6}$ and the lack of information concerning the costs of running such a unit. Current British accounting and information systems in hospitals are organised around departmental budgets and so are not necessarily related directly to the value of the resources consumed. Departments based on a specialty such as cystic fibrosis provide their services by drawing from numerous support departments, which makes costing difficult. This is compounded by the lack of information systems detailing the use of support departments.

This study aimed to determine the costs to the district health authority, family health service authority, and voluntary sources for the 1989-90 financial year and to produce detailed costs for four categories of patients according to their treatment regimen.

\section{Subjects}

Data from 119 patients who had attended the unit regularly from April 1989 to March 1990 were used for the analyses. The patients (69 $(58 \%)$ male and 50 female) had a mean age of $20 \cdot 7$ (SD 5.0, range $16-44$ ) years. The population was divided into four treatment categories: (a) those attending as outpatients every three months (51 patients); (b) outpatients who administered their own intravenous antibiotics at home, usually every three months (28 patients); (c) inpatients who received intravenous antibiotics every three months (32 patients); and $(d)$ patients needing a high level of care who required intravenous antibiotics more frequently than four times a year (eight patients). On isolated occasions patients who administered their own intravenous antibiotics at home were admitted to hospital and consumed inpatient resources; otherwise the four groups were independent.

\section{Procedure}

The analyses covered three areas; (1) the calculation of total costs, (2) the cost of each treatment category, and (3) the contributions made by different bodies, such as the district health authority, the family health service authority, and voluntary sources, in the four categories of patients. Costs were determined for patients in each category by summing the cost of each individual's use of services. Other 
costs-namely, the cost of drugs prescribed by Monsall Hospital and by general practitioners-to patient categories were extrapolated from smaller patient samples.

To obtain accurate data, we measured the resources used by patients in appropriate units and costed them. This required specialised local knowledge, appropriate information and accounting systems, and reports from patients and their families. These processes are detailed as follows: (a) district health authority, (b) Family Health Service Association and (c) Voluntary resources.

\section{DISTRICT HEALTH AUTHORITY COSTS}

These hospital costs comprise the revenue costs (recurrent) and capital charges (annual depreciation cost of buildings and equipment). The identification of revenue costs and the selection of the basis for allocation of costs are described below. The allocation of revenue
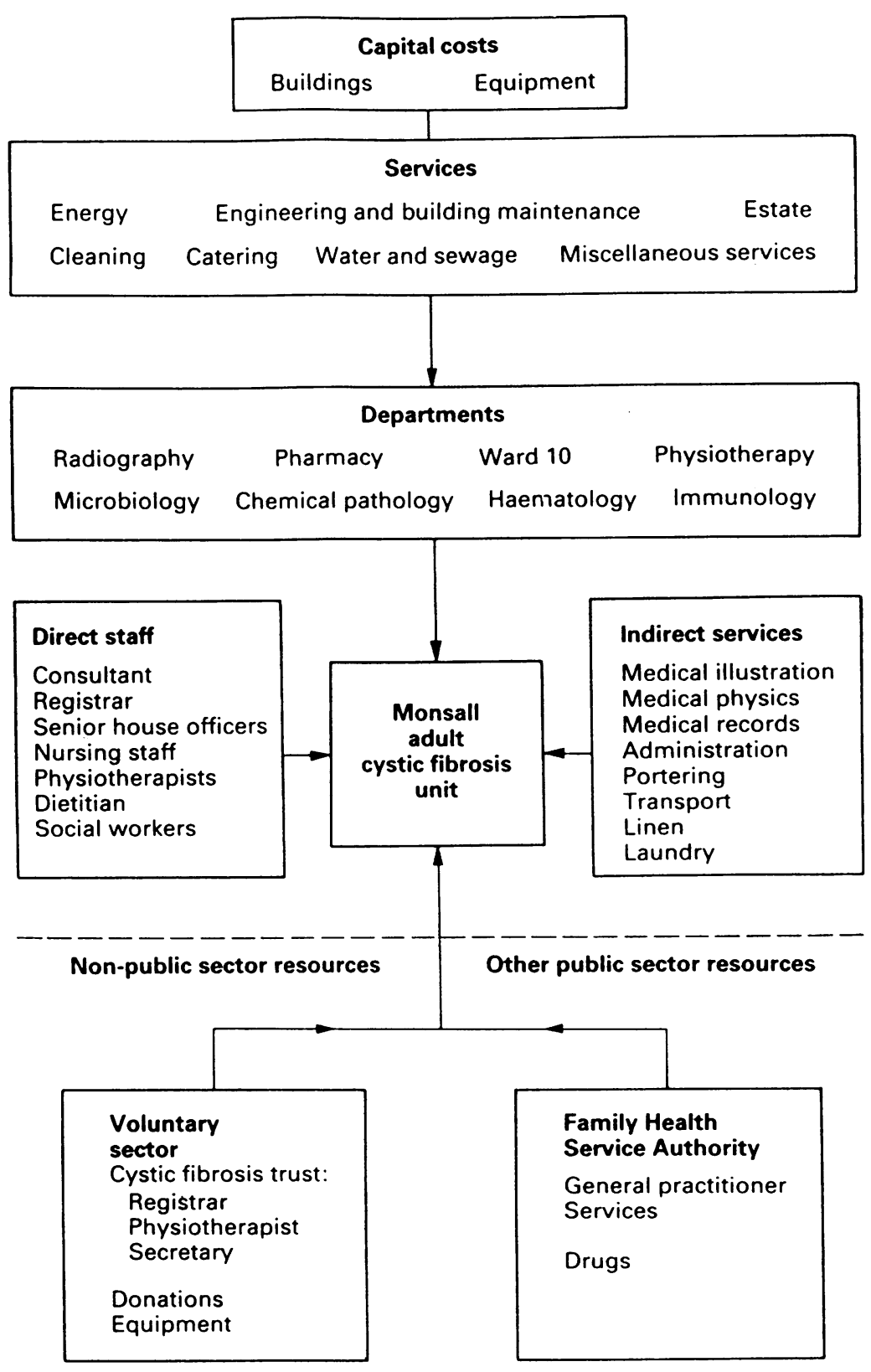

Resources used by Monsall Hospital's adult cystic fibrosis unit. costs were divided into staff, drugs, and procedures and investigations.

\section{Revenue costs}

The departments used by the cystic fibrosis unit and the services used by each department (such as building maintenance, electricity, and cleaning) were identified (figure). The total running cost of each department was obtained from district health authority accounts. These data were validated by patient based costing of labour, which accounts for about three quarters of NHS costs. The total cost of each department was then calculated, and the cystic fibrosis unit's proportion of these costs derived. Fixed costs, such as the proportion of the salary of a radiographer that should be allocated to the cystic fibrosis unit, were based on the proportion of time spent on work for the unit. Variable costs, such as the cost of $x$ ray films, which vary with the needs of the cystic fibrosis unit, were the actual costs incurred. We could not obtain a similar breakdown of total departmental costs from the health service accounts and information systems, so alternative methods for estimating costs were developed and tested for bias. To prevent bias it was essential that the bases used for allocation of costs related as closely as possible to both the fixed and the variable components of a department's total costs. For example, bed days could be applied to radiology costs only if all patients had the same number of radiographs per bed day. The number and type of radiographs associated with cystic fibrosis were therefore obtained for the study period from the patient's notes, and cross checked with the radiology department records. Drug costs and a list of employees, supported departments, and services, with the allocation bases used to apportion costs to the cystic fibrosis unit and to categories of patients according to treatment regimen, are given in table 1. For the distribution of allocated costs to the four treatment categories each patient's use of each support department was measured (staff time, services, and consumables). Support departments did not provide data or costs, but gave data on the time devoted to specialties and information on the units of consumable resources (for example, drugs and dosage).

Staff Staff costs were calculated by estimating the time spent on work related to cystic fibrosis. Clinicians' time was determined from a detailed questionnaire, validated by a diary completed by each staff member for two weeks. The proportion of time devoted to inpatients, outpatients, and shared cystic fibrosis activities was determined. These proportions were then allocated to individual patients according to their outpatient and inpatient attendances, which had been identified for the allocation of physiotherapy and ward costs. Patient's attendances were easily quantified because the physiotherapy department acts as a cystic fibrosis outpatient unit and records all outpatient attendances and inpatient days. Shared time was allocated evenly between all patients. Our social workers dealt solely with the cystic fibrosis unit. An individual patient's allocation 
Table 1 District Health Authority's revenue $(£)$ : total for cystic fibrosis and amount for individual patients, for the 1989-90 financial year

\begin{tabular}{|c|c|c|c|c|c|c|}
\hline & \multirow[b]{2}{*}{ Allocation } & \multicolumn{5}{|c|}{ Category of patient } \\
\hline & & Total & High & IPIV & OPIV & Outpatient \\
\hline DRUGS BILL & Value & 296154 & 59912 & 119794 & 104809 & 11639 \\
\hline \multicolumn{7}{|l|}{ STAFF } \\
\hline Consultant & Time & 27141 & 3015 & 9950 & 8270 & 5906 \\
\hline Registrar & Time & 6408 & 1680 & 4049 & 543 & 136 \\
\hline SHO 1 & Time & 9158 & 2401 & 5786 & 777 & 194 \\
\hline SHO 2 & Time & 3925 & 1029 & 2480 & 333 & 83 \\
\hline SHO 3 & Time & 1090 & 286 & 689 & 92 & 23 \\
\hline Nursing (Ward 10) & No of beds & 70236 & 18416 & 44375 & 5956 & 1489 \\
\hline Social workers & Time & 18068 & 2393 & 6990 & 3972 & 4713 \\
\hline Dietician & Time & 4768 & 1250 & 3013 & 404 & 101 \\
\hline $\begin{array}{l}\text { Physiotherapy } \\
\text { (staff and department) }\end{array}$ & Attendances & 81909 & 17627 & 44542 & 13499 & 6241 \\
\hline \multicolumn{7}{|l|}{ SUPPORT DEPARTMENTS } \\
\hline Ward 10 & No of beds & 37991 & 9961 & 24003 & 3222 & 805 \\
\hline Pharmacy & Items & 16590 & 2185 & 8841 & 4215 & 1349 \\
\hline Radiography & Procedures & 4176 & 480 & 1965 & 1150 & 581 \\
\hline Microbiology & Tests & 3580 & 517 & 1929 & 578 & 556 \\
\hline Haematology & Tests & 2948 & 687 & 1934 & 274 & 53 \\
\hline Chemical pathology & Tests & 5146 & 2009 & 2661 & 356 & 120 \\
\hline Immunology & Tests & 2587 & 1009 & 1464 & 91 & 23 \\
\hline Medical physics & Bed days & 1270 & 333 & 802 & 102 & 27 \\
\hline \multicolumn{7}{|l|}{ SERVICES } \\
\hline Medical records & Bed days & 3094 & 811 & 1955 & 262 & 66 \\
\hline Administrative office & Bed days & 9126 & 2393 & 5766 & 774 & 193 \\
\hline Portering & Bed days & 7422 & 1946 & 4690 & 629 & 157 \\
\hline Transport & Bed days & 824 & 216 & 521 & 70 & 17 \\
\hline Laundry & Bed days & 1210 & 317 & 764 & 103 & 26 \\
\hline Linen & Bed days & 367 & 96 & 232 & 31 & 8 \\
\hline Medical illustration & Bed days & 276 & 72 & 175 & 23 & 6 \\
\hline \multirow{3}{*}{\multicolumn{2}{|c|}{$\begin{array}{l}\text { Total } \\
\text { No of patients } \\
\text { Cost per patient }\end{array}$}} & 615564 & 131041 & 299370 & 150541 & 34512 \\
\hline & & 119 & & 32 & 28 & 51 \\
\hline & & 5172 & 16380 & 9355 & 5376 & 677 \\
\hline
\end{tabular}

Ward 10-ward for inpatients with cystic fibrosis; High-high level of care patient; IPIV-inpatient receiving intravenous antibiotics; OPIV-outpatient receiving intravenous antibiotics.

of time was determined on a five point rating scale from "never seen" to "highly demanding." Within each category patients were placed on a scale from 1 to 100 and each patient's percentage of social work time was then calculated. Within the four treatment categories a similar distribution of a patient's proportion of social work time was observed. Nursing time (inpatient only) was allocated to the unit and individual patients on the basis of cystic fibrosis beds (10) and bed days respectively. The dietician estimated that one third of her time was devoted to patients with cystic fibrosis. At the time of the study only inpatients were visited so costs were allocated to individual patients according to the number of days in hospital. The costs of staff within each department were included in the total costs of the department.

Dispensed drugs The total cost of drugs dispensed was obtained from the pharmacy's computer, which itemises and prices all drugs associated with cystic fibrosis. The cost of individual patients' prescriptions was difficult to ascertain and time consuming, so all dispensed inpatient and outpatient items were identified from drug sheets, patients' notes, and prescriptions from the pharmacy for a random sample of 40 patients (10 from each treatment category) and allocated accordingly to the four treatment categories. Drugs prescribed for the final six months of the 1989-90 financial year were recorded. As there were only eight "high level of care" patients, data on two patients who had died recently were included in the analysis.

Medical procedures and investigations These costs were the most difficult to identify. The total number of investigations and procedures undertaken during the year were determined from the patients' notes and validated, where possible, from records from the relevant department. The costs for patients with cystic fibrosis were calculated from the total costs of the pathology and radiology departments and the total number of investigations and procedures performed on patient with cystic fibrosis that year. There was little variation between patients for the types of radiographs and tests, but the frequency of use differed between clinical groups. The pathology costs from the North Manchester Hospital were validated with the price per test-for example, full blood count or measurement of lipidsobtained from the hospital's resource management initiative; they were similar to those calculated by the first method. The allocation of costs to individual patients and to treatment categories was estimated from each patient's proportion of the cystic fibrosis unit's investigations carried out in each department.

\section{Capital charges}

Capital costs of equipment and buildings have not previously been identified by district health 
Table 2 District Health Authority total and individual patient capital costs $(£)$ for the 1989-90 financial year

\begin{tabular}{llrrrrr}
\hline & & \multicolumn{5}{l}{ Category of patient } \\
\cline { 3 - 7 } Department & Allocation & Cystic fibrosis & High & IPIV & OPIV & Outpatient \\
\hline Radiography & Procedures & 7694 & 885 & 3620 & 2118 & 1071 \\
Pharmacy & Items & 528 & 70 & 281 & 134 & 43 \\
Physiotherapy & Attendances & 27684 & 5958 & 15054 & 4562 & 2110 \\
Ward 10 & Beds & 14882 & 3902 & 9402 & 1263 & 315 \\
\hline Totals & & 50788 & 10815 & 28357 & 8077 & 3539 \\
No of patients & & 119 & 8 & 32 & 28 & 51 \\
Cost per patient & & 427 & 1352 & 886 & 288 & 69 \\
\hline
\end{tabular}

Ward 10-ward for inpatients with cystic fibrosis; High-high level of care patient; IPIV-inpatient receiving intravenous antibiotics; OPIV—outpatients receiving intravenous antibiotics.

authorities. Health districts have had to identify such costs since the implementation of the NHS and Community Care Act 1990-a conventional accounting practice. In a preliminary valuation undertaken by the District Health Authority assets at Monsall Hospital were valued at the cost of replacement, discounted over different time periods depending on the asset, to give an annual capital charge for each department. The value of assets outside Monsall Hospital was not obtained, but this represents a small part of the capital assets used by the cystic fibrosis unit. This leads to a small underestimate of such resources. Capital charges were allocated to the cystic fibrosis unit and treatment categories by the method used to allocate revenue costs for each laboratory department.

FAMILY HEALTH SERVICE AUTHORITY COSTS Patients with cystic fibrosis generally restrict contact with their general practitioner to repeat prescriptions. We concentrated solely on drug costs and did not attempt to cost general practitioners' time or Family Health Service Authority capital or administration costs. These calculations were based on the results of a sample of 50 patients (15 outpatients, 14 outpatients administering intravenous antibiotics, 16 inpatients, and five patients needing a high level of care). The average cost for each treatment category was then extrapolated to all the patients of the cystic fibrosis unit. The identification and costing of all drugs which the patient took regularly and repeat courses dispensed outside Monsall were obtained from the patients' notes and interviews of patients and close companions. Notes were examined to determine the pattern of routine drug prescribing on the basis of letters, drug sheets, and prescriptions. Patients' reports served as a cross check on these findings. From this the total costs and the average costs for each of the four treatment categories were obtained.

\section{VOLUNTARY COSTS}

There were two sources of voluntary fundingthe Cystic Fibrosis Research Trust and the Monsall cystic fibrosis unit's fund. The Cystic Fibrosis Research Trust funds a registrar, physiotherapist, and part time secretary. Voluntary donations to the unit are primarily spent on equipment, and account for $90 \%$ of the equipment in the physiotherapy department. The costs of staff salaries were allocated to the four treatment categories in the same way as costs for staff funded by the District Health Authority. All other voluntary inputs were allocated by the patients' percentage of physiotherapy attendances.

\section{Results}

DISTRICT HEALTH AUTHORITY, VOLUNTARY, AND FAMILY HEALTH SERVICE AUTHORITY COSTS

The revenue costs to the District Health Authority for cystic fibrosis for the 1989-90 financial year are given in table 1 . Also given are the costs incurred for each employee, department, or service; the cost for each of the four treatment categories; and the expenditure for the average patient and for those in each treatment category. A breakdown of the District Health Authority's capital costs and voluntary resources are given in tables 2 and 3 . The results of the Family Health Service Authority's total expenditure on drugs for patients with cystic fibrosis,

Table 3 Voluntary resources ( $£$ ): total for cystic fibrosis and amount for individual patients, for the 1989-90 financial year

\begin{tabular}{lllllll}
\hline & & \multicolumn{2}{l}{ Category of patient } & & \\
\cline { 5 - 7 } Resource & Allocation & Total & High & IPIV & OPIV & Outpatient \\
\hline Junior physiotherapist & Attendances & 13200 & 2841 & 7178 & 2175 & 1006 \\
Registrar & Time & 18953 & 2106 & 6948 & 5775 & 4124 \\
Secretary (part time) & Bed days & 4000 & 1050 & 2527 & 339 & 84 \\
Voluntary donations & Attendances & 13000 & 2798 & 7067 & 2143 & 992 \\
\hline Totals & & 49153 & 8795 & 23720 & 10432 & 6206 \\
No of patients & 119 & 8 & 32 & 28 & 51 \\
Cost per patient & 413 & 1099 & 741 & 373 & 122 \\
\hline
\end{tabular}

Ward 10-ward for inpatients with cystic fibrosis; High-high level of care patient; IPIV-inpatient receiving intravenous antibiotics; OPIV—outpatient receiving intravenous antibiotics. 
Table 4 Total cost ( $($ ) of treating patients attending the Monsall adult cystic fibrosis unit for the 1989-90 financial year

\begin{tabular}{|c|c|c|c|c|c|c|}
\hline \multirow[b]{2}{*}{ Sector } & \multirow[b]{2}{*}{ Total } & \multirow[b]{2}{*}{ Average } & \multicolumn{4}{|c|}{ Category of patient } \\
\hline & & & High & $I P I V$ & OPIV & Outpatient \\
\hline (a) Revenue DHA & 615464 & 5172 & 16380 & 9355 & 5376 & 677 \\
\hline (b) Capital DHA & 50788 & 427 & 1352 & 886 & 288 & 69 \\
\hline (c) FHSA & 265241 & 2229 & 1124 & 2519 & 2769 & 1924 \\
\hline (d) Voluntary & 49153 & 413 & 1099 & 741 & 373 & 122 \\
\hline Total DHA $(a+b)$ & 666252 & 5599 & 17732 & 10241 & 5664 & 746 \\
\hline Total NHS $(a+b+c)$ & 931493 & 7828 & 18856 & 12760 & 8433 & 2760 \\
\hline Total Monsall $(a+b+d)$ & 715405 & 6012 & 18831 & 10982 & 6037 & 868 \\
\hline Overall total & 980646 & 8241 & 19955 & 13501 & 8806 & 2792 \\
\hline
\end{tabular}

DHA-District Health Authority; FHSA-Family Health Service Authority.

including value added tax of $15 \%$, and analyses of costs related to treatment regimens are given in table 4 . Also contained in table 4 are figures for the total resources obtained from all sectors.

TOTAL DISTRICT HEALTH AUTHORITY, NATIONAL HEALTH SERVICE, AND MONSALL CYSTIC FIBROSIS UNIT'S COSTS

The total cost of the Monsall adult cystic fibrosis unit varies according to the perspective taken. The total District Health Authority's cost (hospital costs) is simply the capital and revenue costs ( $£ 666252$ ), of which the capital charge accounts for $8 \%$ of the total. This appears to be a good estimate given that North Manchester District Health Authority's average capital charge is $12 \%$ of total costs, ${ }^{7}$ and Monsall Hospital has a smaller capital input owing to the lower value of its buildings. The overall costs of treating patients at the Monsall cystic fibrosis unit $(£ 980646)$ includes resources from all sectors (table 4). Of this, $57 \%$ ( $£ 561395)$ was spent on medication. The cost of the Monsall cystic fibrosis unit was $£ 715405$ (District Health Authority provision plus voluntary support).

INDIVIDUAL PATIENTS' COSTS

When patients were categorised by treatment regimen wide variations in resource requirements were evident. From the total hospital costs (excluding Family Health Service Authority drugs costs) the average patient's expenditure ranged from $£ 868$ for an outpatient to $£ 18831$ for a patient needing a high level of care; the average cost for the 1989-90 financial year was $£ 6012$. This low average cost reflects the high proportion of patients currently in the outpatient category $(43 \%)$. The average cost was about the same as the cost of treating an outpatient requiring intravenous antibiotics at home every three months $(£ 6037)$. A patient who came into hospital for three monthly intravenous antibiotic treatment cost $£ 10982$ ( 1.8 times the cost for the average patient). The resources required for a patient who required a high level of care was 3.1 times the cost for the average, whereas an outpatient receiving three monthly consultations cost only $14 \%$ of the average cost. The resources required to care for a patient with cystic fibrosis in the final stage of the disease was 21.7 times the resources needed to care for an outpatient.

Although hospital costs decreased substan- tially from the patients receiving high levels of care to those who attend the clinic as outpatients, the Family Health Service Authority's costs for the four treatment groups followed a reverse pattern, with the greatest costs incurred by outpatients $(69 \%$ of the total outpatient cost), followed by patients administering their own intravenous antibiotics at home $(32 \%)$, inpatients receiving intravenous antibiotics (19\%), and finally the "high level of care" patients $(6 \%)$.

\section{Discussion}

The total cost of caring for the 119 patients attending the Monsall Hospital adult cystic fibrosis unit for the 1989-90 financial year (NHS and voluntary resources) amounted to almost $£ 1$ million. Costs of drugs, medical investigations and procedures, and staff accounted for $57 \cdot 2 \%, 20 \cdot 1 \%$, and $19 \cdot 7 \%$ of the total cost. The average cost of a patient was $£ 8241$ a year, with large variations between the four treatment categories. These costs were determined by methods that generated comprehensive patient based and non-routine information. Current District Health Authority information and accounting systems are not designed to produce this type of detailed data based on treatment categories. The work was extremely time consuming and monotonous-searching through individual patients' pharmacy prescriptions, for example-and required considerable cooperation from staff from various disciplines.

There were problems in generating appropriate bases for the allocation of costs and more fundamentally in the flow of information between consultant and accountant. It was a relatively easy task for the physician concerned in the care of patients to categorise these according to four clinically defined treatment regimens, and to revise these initial costings for each category for the next financial year, thereby enabling accountants to charge purchasing districts accurately for the resources consumed. Usually only one or two patients change treatment categories during a year. Indeed, the four treatment groups were virtually independent throughout this study period.

This study enabled our unit to acquire a separate contract, which allocates district charges on the basis of both the number and the 
treatment category of patients referred. Our cystic fibrosis unit had previously been a designated regional specialty and there were no previous accurate district health authority costs to compare with our data. When there are large variations in patients' disease severity or treatments (or both) within a specialised unit, the importance of not using an "average patient" cost is apparent. The cost for a patient receiving a high level of care was more than 20 times greater than that for an outpatient attending four times a year.

These findings have facilitated the predication of short and long term financial requirements for cystic fibrosis. Given that the drug bill amounted to $41 \%$ of the hospital cost and $57 \%$ of the total cost of caring for patients with cystic fibrosis, in the future the additional cost of extra patients will be determined primarily by the drugs they require. As the number of patients increases fixed costs will be more widely spread, reducing the average cost of caring for an adult with cystic fibrosis. With the ability to anticipate increased spending over a patient's lifetime collaboration between physicians and managers may lead to more accurate and specific predictions of costs.

The Royal College of Physicians report on cystic fibrosis in adults ${ }^{8}$ supports the development of specialist centres. With an increasing demand for specialist care for adults with cystic fibrosis our clinic has within a year of the period of data collection increased to 165 patients. The improving survival of patients with cystic fibrosis, however, brings with it clinical and psychosocial complications, ${ }^{9}$ all of which required additional resources. Voluntary funding supported $5 \%$ of our unit's required resources, which is a small percentage of the total cost. The benefit from these resources is very great, however, since they fund three key members of staff and provide essential equipment. Although their importance is recognised, the wider costs borne by patients, their families, and society-for example, for equipment, prescriptions, and travel-have not been evaluated.

Many of our patients colonised with Pseudomonas aeruginosa are treated with intravenous antibiotics every three months to try to prevent recurrent infective exacerbations and further lung damage, though the benefit of this regimen is not proved. Although this approach may increase patients' costs it may also prevent hospital admission for recurring emergencies. This analysis has been structured as a framework for other units to base their costs on and they can adjust their costs according to local medical policy. There are no data concerning non-specialist costs of cystic fibrosis care. If patients treated within their own districts are receiving the same high quality of care as patients in specialist centres, costs should not be appreciably greater. Much intravenous treatment, however, is managed by centres on a domiciliary basis. These patients need to be carefully selected and require considerable physiotherapy and nursing inputs. This may greatly reduce the costs incurred by hospital admission and save a considerable amount of money. Usually, however, only specialist centres with appropriate support facilities can practise this policy.

This study forms a framework that may be applied to other specialties as the principles and problems of detailed costing are likely to be similar. The major problem we identified was a lack of investment in the information systems before adoption of the recent National Health Service reforms to produce even basic data, such as on radiographs identified by specialty. If prices are to be used to measure efficiency in a health service, information and accounting systems must be able to link the cost of the resources consumed to the prices charged to district health authorities. Our study cost about $£ 6000$, which was chiefly the cost of a health economist paid from voluntary funds and other research staff time. This cost was less than $1 \%$ of the district health authority's annual cost for cystic fibrosis. Similar studies in other units should help to generate separate discriminative contracts for cystic fibrosis, the ability to predict and plan future resource requirements, and the knowledge that the charges accurately reflect the resources consumed.

We are indebted to Audrey Grimshaw and Cynthia Hovington for their painstaking searches through patients' notes and records; to staff at Monsall Hospital in the pharmacy and in radiography, pathology, physiotherapy, and social work departments and ward 10; and the accountants at North Manchester District Health Authority. We thank the Cystic Fibrosis Research Trust for their financial support.

1 British Paediatric Association Working Party on Cystic Fibrosis. Cystic Fibrosis in the United Kingdom 19771985: an improving picture. BMJ 1988;297:1599-602.

2 Phelan P, Hey E. Cystic fibrosis mortality in England and Wales and in Victoria, Australia, 1976-80. Arch Dis Child 1984;59:71-83.

3 Warwick WJ. Prognosis for survival with cystic fibrosis: the effects of early diagnosis and cystic fibrosis centre care. Acta Paediatr Scand (suppl) 1982;301:27-31

4 Nielson $\mathrm{OH}$, Schiotz PO. Cystic fibrosis in Denmark in the period 1945-1981: evaluation of centralized treatment. Acta Paediatr Scand (suppl) 1982;301:107-19.

5 Webb AK. The difficulties of treating cystic fibrosis in adults. $J R$ Soc Med (suppl) 1987;80:47-50.

6 Department of Health and Social Security. Working for patients. London: HMSO. (Cm 555.)

7 Moore W. A site dearer for the inner city areas. Health Service Journal 1991;101:15.

8 Royal College of Physicians. Cystic fibrosis in adults: recommendations for care of patients in the UK. London: Royal College of Physicians of London, 1990.

9 Hodson ME. Managing adults with cystic fibrosis: chest medicine's success story. $B M J$ 1989;298:471-2. 